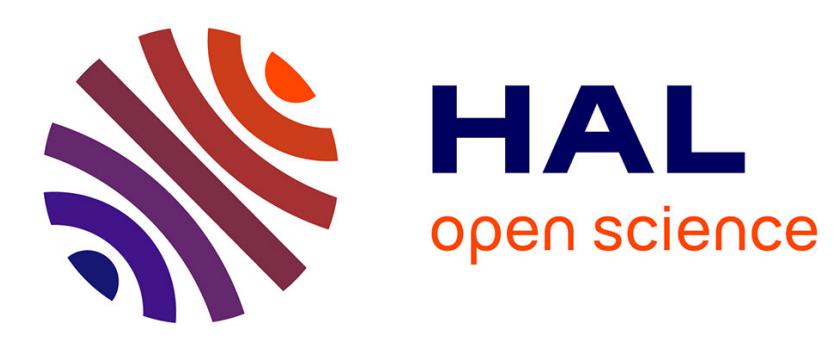

\title{
LecB, a High Affinity Soluble Fucose-Binding Lectin from Pseudomonas aeruginosa
}

Émilie Gillon, Annabelle Varrot, Anne Imberty

\section{To cite this version:}

Émilie Gillon, Annabelle Varrot, Anne Imberty. LecB, a High Affinity Soluble Fucose-Binding Lectin from Pseudomonas aeruginosa. Methods in Molecular Biology, 2020, Lectin purification and analysis (2132), pp.475-482. 10.1007/978-1-0716-0430-4_46 . hal-02554312

\section{HAL Id: hal-02554312 https://hal.science/hal-02554312}

Submitted on 25 Apr 2020

HAL is a multi-disciplinary open access archive for the deposit and dissemination of scientific research documents, whether they are published or not. The documents may come from teaching and research institutions in France or abroad, or from public or private research centers.
L'archive ouverte pluridisciplinaire HAL, est destinée au dépôt et à la diffusion de documents scientifiques de niveau recherche, publiés ou non, émanant des établissements d'enseignement et de recherche français ou étrangers, des laboratoires publics ou privés. 


\title{
LecB, a High Affinity Soluble Fucose-Binding Lectin from Pseudomonas aeruginosa
}

\author{
Emilie Gillon, Annabelle Varrot \& Anne Imberty* \\ Univ. Grenoble Alpes, CNRS, CERMAV, 38000 Grenoble, Alpes \\ *Author for correspondence: Anne Imberty, anne.imberty@cermav.cnrs.fr
}

Running Head: LecB/PA-IIL from Pseudomonas aeruginosa

Key words: Pseudomonas aeruginosa, soluble lectin, fucose, blood-group oligosaccharide, microcalorimetry,

\begin{abstract}
LecB/PA-IIL (Pfam PF07472) from bacterium Pseudomonas aeruginosa is a fucose-binding lectin with unusual high affinity for glycans. The occurrence of LecB and related proteins is limited to few opportunistic bacterial species, some of them being responsible for severe infections in immune compromised patients. This lectin is therefore of interest as a target for the design of anti-infectious compounds, but can also be used for research and biotechnology. LecB is a small protein that can be produced in good quantity in recombinant system and purified by affinity chromatography.
\end{abstract}

\section{Introduction}

Pseudomonas aeruginosa is one of the main human opportunistic pathogens and is responsible of infections such as folliculitis, keratitis, otitis but also pneumopathies in cystic fibrosis patients resulting in morbidity and mortality $[1,2]$. Among several virulence factors, P. aeruginosa produces two soluble lectins named LecA (or PA-IL) and LecB (or PA-IIL) that are specific for galactose and fucose, respectively [3]. LecB consists of four subunits of $11.73 \mathrm{kDa}$, each with a high affinity binding site for L-fucose and fucose-containing glycoconjuguates [4]. The lectin also binds to D-mannose but with lower affinity. LecB is produced in the cytoplasm of $P$. aeruginosa but has been shown to be located in the outer membrane and involved in biofilm formation [5].

The crystal structure of LecB in complex with fucose [6] and with mannose [7] uncovered the molecular basis of its ligand recognition. LecB forms homotetramer, each monomer presenting a fucose binding site with two calcium ions that are directly involved in carbohydrate coordination. LecB displays exceptionally high affinities for fucose, with $K_{\mathrm{d}}$ values in the micromolar range [8]. It binds to a large range of fucosylated antigens $(\mathrm{ABH}$, Lewis, P and I systems) present on human tissues and in human milk $[9,10]$ with highest reported affinity in the nM range for Lewis a epitope [9], and for biantennary $N$-glycans presenting two H-type epitopes at the extremities of branches [11]. LecB is a target of interest for anti-adhesion and anti-biofilm compounds and the search for glyco-derived drugs with potential therapeutical application is very active $[12,13]$.

As other lectins with specificity towards human glycans, LecB is also of biotechnical interest for the purification of glycoproteins or the labelling of glycoconjugates on tissues. LecB is now included in the few lectin-arrays proposed in different laboratories for the fine characterization of glycans. Due to its propensity to easily form crystals, LecB has been utilized as a template for structural determination of smaller biomolecules that are difficult to crystallize by themselves : after attachment of a fucose residue, modified DNA duplexes or short anti-bacterial peptides could be co-crystallized with LecB and structurally characterized $[14,15]$. 

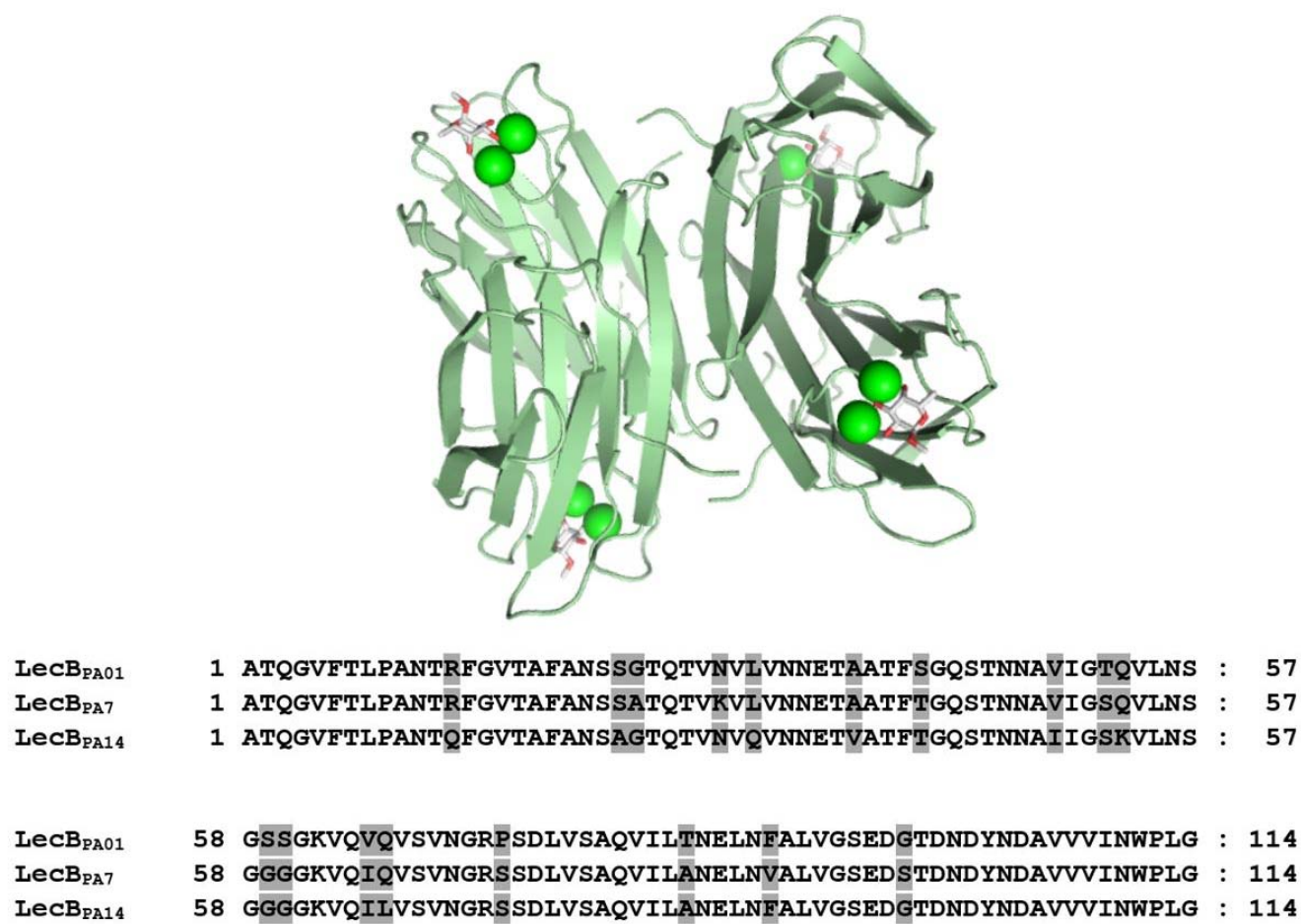

Figure 1: Alignment of amino acid sequences for LecB sequences and crystal structure of LecBPA14 in complex with a-methyl-fucoside (5A6X). Protein is represented by ribbon, monosaccharides by sticks and calcium ions by spheres.

Most studies have been performed using LecB from $P$. aeruginosa PAO1 strain. However, recent works demonstrated sequence variations in $\mathrm{LecB}$ when analyzing the many isolates from clinical or environmental origin. Three different clusters of sequences were identified, represented by LecB from PAO1, PA7 and PA14 virulent strains [11, 16]. Some of the amino acid variations are located near the fucose binding site but affect only slightly the specificity and affinity of LecB. LecB-like lectins are also present in a limited number of bacteria from the Ralstonia, Chromobacterium and Burkholderia species. CV-IIL from Chromobacterium violaceum is very similar to LecB [17], while RS2L from Ralstonia solanacearum is specific for mannoside [18]. Such variation in specificity has been demonstrated to be due to one amino acid variation at position 22 [19]. Burkholderia cenocepacia hosts four different LecBlike proteins with dimeric association of lectin and extension by several other proteins [20, 21]. The details of production and characterization listed here can be therefore applied, with small adjustments to the whole family of LecB-like lectins.

\section{Materials}

Prepare all solutions using analytical grade reagents and ultrapure water and then filter on $0.22 \mu \mathrm{M}$ membrane. Follow waste disposal regulations.

\subsection{LecB Production}

1. Dry block heater at $42{ }^{\circ} \mathrm{C}$.

2. Incubation shaker with cooling option.

3. $250 \mathrm{~mL}$ and $3 \mathrm{~L}$ baffled Erlenmeyer flasks.

4. Competent bacteria : Escherichia coli BL21(DE3) 
5. Plasmid: pET25b-LecB

6. Lennox L Broth Base.

7. $100 \mathrm{mg} / \mathrm{mL}$ ampicilline.

8. 1 M Isopropyl- $\beta$-D-thiogalactopyranoside (IPTG).

9. $1 \mathrm{~L}$ polycarbonate centrifuge bottle.

10. $50 \mathrm{~mL}$ sterile conical centrifuge tubes.

11. Centrifuge with adapted rotors.

\subsection{LecB Purification}

1. Endonuclease such as Benzonase or Denarase at 250 units $/ \mu \mathrm{L}$.

2. Rotating wheel.

3. One shot table top cell disruptor (Constant systems Ltd).

4. $35 \mathrm{~mL}$ centrifuge tube and centrifuge wth rotor going to $24,000 \times g$

5. $0.45 \mu \mathrm{m}$ PES syringe filter.

6. C10/10 column with flow adapter (GE Healthcare Life Sciences).

7. Equilibration buffer : $20 \mathrm{mM}$ Tris $\mathrm{pH} 7.5100 \mathrm{mM} \mathrm{NaCl}$ and $100 \mu \mathrm{M} \mathrm{CaCl} 2$ (see Note 1).

8. Elution buffer : $20 \mathrm{mM}$ Tris pH $7.5100 \mathrm{mM} \mathrm{NaCl}$ and $100 \mathrm{mM}$ D-Mannose.

9. Low or Medium-Pressure Chromatography Systems such as Akta Prime (GE Healthcare Life Sci) or NGC (Bio-Rad).

10. $5 \mathrm{~mL}$ collection tubes.

11. Snakeskin dialysis tubing 3500 MWCO (Thermo Fisher Scientific).

$12.20 \%$ ethanol

\subsection{Quality Control by Evaluation of Affinity}

1. ITC200 Microcalorimeter (Malvern Panalytical).

2. Nanodrop 2000 Spectrophotometer (Thermo Scientific).

3. ITC buffer : $20 \mathrm{mM}$ Tris $\mathrm{pH} 7.5100 \mathrm{mM} \mathrm{NaCl}$ and $100 \mu \mathrm{M} \mathrm{CaCl} 2$.

4. $\alpha$-methyl fucopyranoside (SIGMA 32198).

\section{Methods}

\subsection{LecB Production}

\subsubsection{Transformation and Preculture}

1. The plamid pET25b-LecB has been obtained from template DNA from Pseudomonas aeruginosa ATCC 33347 as previously described [8] and is available upon request.

2. Add $1 \mu \mathrm{L}$ of pET25b-LecB plasmid to $100 \mu \mathrm{L}$ of competent BL21(DE3) cells before $10 \mathrm{mn}$ incubation on ice.

3. Heat shock at $42{ }^{\circ} \mathrm{C}$ for $45 \mathrm{~s}$ before a 3 min stay on ice.

4. Add $900 \mu \mathrm{L}$ of liquid LB and incubate horizontally for $1 \mathrm{hr}$ at $37^{\circ} \mathrm{C}$ with shaking at $180 \mathrm{rpm}$.

5. Spread $100 \mu \mathrm{L}$ on a petri dish with LB-agar and $100 \mu \mathrm{g} / \mathrm{mL}$ ampicilline and incubate at $37^{\circ} \mathrm{C}$ overnight.

6. Transfer 1 colony to $10 \mathrm{~mL}$ liquid LB containing $100 \mu \mathrm{g} / \mathrm{mL}$ ampicilline and incubate overnight with shaking at $180 \mathrm{rpm}$.

\subsubsection{Culture}

1. Inoculate $1 \mathrm{~L}$ of liquid LB supplemented with $100 \mu \mathrm{g} / \mathrm{mL}$ ampicilline in 3 liters Erlenmeyer with the overnigth preculture.

2. Incubate at $37{ }^{\circ} \mathrm{C}$ with shaking at $180 \mathrm{rpm}$ until $\mathrm{OD}_{600 \mathrm{~nm}}$ reached 0.6.

3. Switch the temperature to $30^{\circ} \mathrm{C}$, induce expression by adding $0.25 \mathrm{mM}$ IPTG and culture for 3 hours at $180 \mathrm{rpm}$. 
4. Centrifuge at $6,000 \times g, 4{ }^{\circ} \mathrm{C}$ for $15 \mathrm{~min}$.

5. Resuspend the pellet in $35 \mathrm{~mL}$ liquid $\mathrm{LB}$, transfer in $50 \mathrm{~mL}$ sterile conical tube and centriguge $6,000 \times g$ for $10 \mathrm{~min}$.

6. Remove supernatant and store the pellet at $-20^{\circ} \mathrm{C}$ untill use.

\subsection{LecB Purification}

1. Resuspend the pellet in $30 \mathrm{~mL}$ of equilibration buffer.

2. Break the cells using a one shot table top cell disruptor at a pressure of $1.9 \mathrm{kbar}$.

3. Centrifuge $24,000 \times g, 30 \mathrm{~min}$ at $4{ }^{\circ} \mathrm{C}$ to clarify the sample.

4. Filter the supernatant on $0.45 \mu \mathrm{m}$ with syringe filter.

5. Equilibrate a $10 \mathrm{~mL}$ D-Mannose agarose resin packed in $\mathrm{C} 10 / 10$ column connected to automated chromatography system such as NGC system with 5 column volumes $(\mathrm{CV})$ of equilibration buffer at a flowrate of $1 \mathrm{~mL} / \mathrm{min}$.

6. Load the filtered supernatant at a flow rate of $1 \mathrm{~mL} / \mathrm{min}$ and collect the flowthrough.

7. Rinse the column with the equilibration buffer to wash out contaminants until the baseline of $\mathrm{OD}_{280 \mathrm{~nm}}$ on the chromatogram stabilized to a low value ( $3 \mathrm{~mL} / \mathrm{min}$ flowrate).

8. Elute the protein with the elution buffer using a flowrate of $3 \mathrm{~mL} / \mathrm{min}$ and collect fraction of $5 \mathrm{~mL}$.

9. Rinse the column with $3 \mathrm{CVs}$ of ultrapure water at a flowrate of $3 \mathrm{~mL} / \mathrm{min}$ and $2 \mathrm{CVs}$ of $20 \%$ ethanol at flowrate of $1 \mathrm{~mL} / \mathrm{min}$ prior storage at $4{ }^{\circ} \mathrm{C}$.

10. Collect the fractions of the eluted peak and dialyzed against ultrapure water for 1 week, changing the bath each morning and evening.

11. Lyophilize protein and store at $-20^{\circ} \mathrm{C}$ (see Note 2).

\subsection{Quality Control by Evaluation of Affinity}

Isothermal titration calorimetry (ITC) is an analytical technique, which is considered as the gold standard for analyzing intermolecular interactions in solution. It is widely used for quality control in biotechnology since it gives access to quantitative analysis of the interaction of a protein with its ligand. A single experiment allows to determine stoichiometry $(n)$, binding enthalpy $(\Delta \mathrm{H})$, and affinity (i.e. dissociation constant, $K_{\mathrm{d}}$ ). Since the method is based on the heat released or absorbed in the binding process, it is very well suited for protein carbohydrate interaction, where the large number of hydrogen bonds result in strong exothermic signal [22].

\subsubsection{Sample Preparation :}

1. Prepare $400 \mu \mathrm{L}$ of $\mathrm{LecB}$ at $50 \mu \mathrm{M}$ in ITC buffer from the lyophilized protein. Weight $1.5 \times$ excess amount of the necessary protein, dissolve in the corresponding volume of buffer, centrifuge 7,000 $\times \mathrm{g}$ for $5 \mathrm{~min}$.

2. Recover the supernatant and determine the precise concentration by spectroscopy at $280 \mathrm{~nm}$ using a molecular weight of 11,732 daltons per monomer and a theoretical molar extinction coefficient of 6,990 corresponding to Absorbance 0.1 $\%(=1 \mathrm{~g} / \mathrm{L})$ of 0.596 .

3. Ajust the concentration to $50 \mu \mathrm{M}$ with the ITC buffer.

4. Prepare $70 \mu \mathrm{L}$ of $0.5 \mathrm{mM}$ of $\alpha$-methyl fucoside ( $\alpha \mathrm{MeFuc}$ ) in the same buffer as the lectin (see Note 3).

5. Degas all samples.

\subsubsection{ITC Experiment}

1. Fill the measuring cell with $50 \mu \mathrm{M}$ LecB solution and the syringe with $0.5 \mathrm{mM} \alpha \mathrm{MeFuc}$ solution. Cell volume is $200 \mu \mathrm{L}$ and syringe volume is $40 \mu \mathrm{L}$.

2. Setup the parameters to DP 8 , injection number 20 , injection volume of $1 \mu \mathrm{L}$ for the first one and $2 \mu \mathrm{L}$ for all following ones with an injection delay of $120 \mathrm{~s}$. 
3. Use the Origin software of the microcalorimeter for data analysis (see Note 4). The default parameters with a "one-site" model is fully compatible with the present experiments. Data will be obtained as indicated in Fig. 2 when clicking on the "ITC data" button (see Note 5).

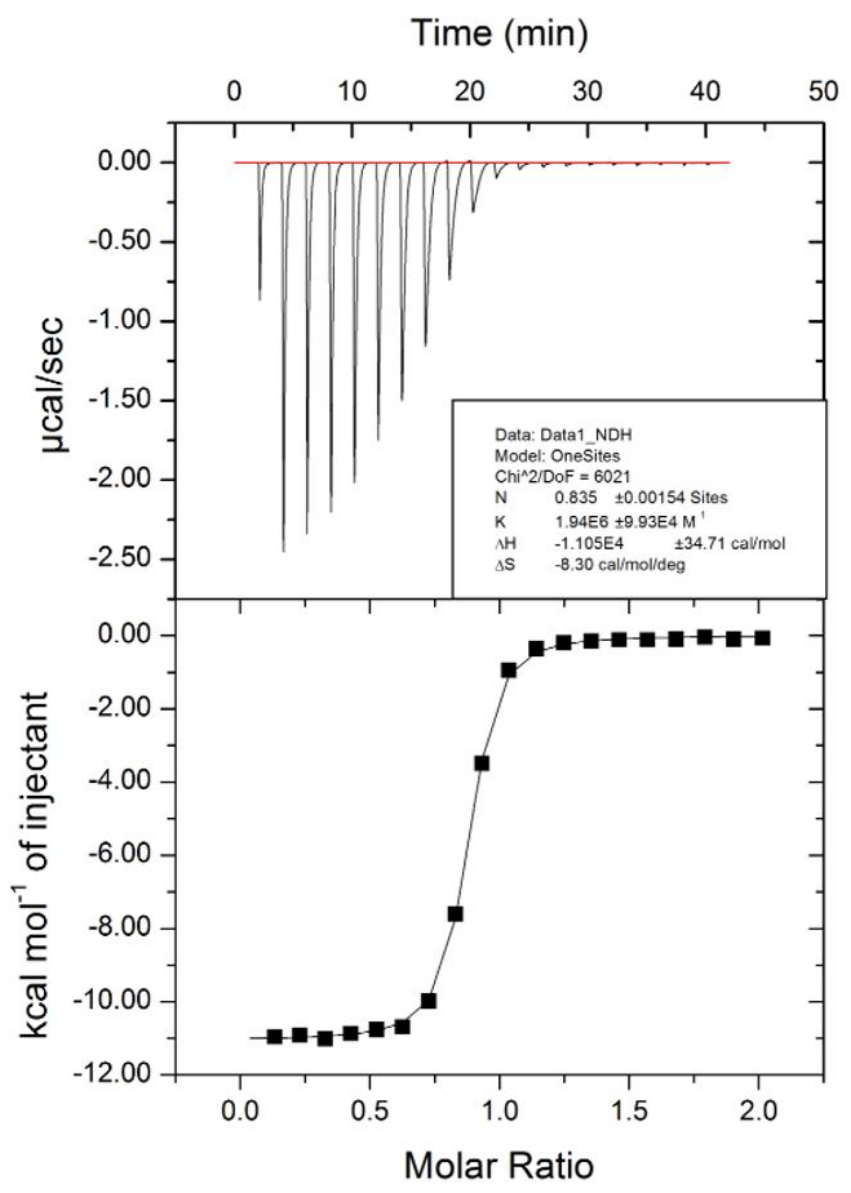

Figure 2: Typical ITC experiment of titration of LecB $B_{P A O I}$ by $\alpha$-methyl-L-fucoside with thermogram (top) and integrated data (bottom). The observed stoichiometry of 0.835 indicates here that $16.5 \%$ of the protein is inactive. This does not affect the determination of thermodynamics constant, since they are expressed as a function of the concentration of ligand. The enthalpy of binding is $-11.05 \mathrm{Kcal} / \mathrm{mol}(-46 \mathrm{~kJ} / \mathrm{mole})$ with a weak unfavorable contribution of entropy $\Delta S$ of $-8.3 \mathrm{cal} / \mathrm{mol} / \mathrm{deg}$ (ie $T \Delta S=-10.3 \mathrm{~kJ} / \mathrm{mol}$ ) which is in full agreement with previous data [23].

4. Quality control is performed by comparing the obtained thermodynamic of binding with literature [23]. LecB was reported to have a submicromolar affinity for aMeFuc $\left(K_{d}=430\right.$ $\mathrm{nM})$ with strong enthalpy $(\Delta \mathrm{H}=-41.3 \mathrm{~kJ} / \mathrm{mol})$ and a stoichiometry corresponding to approximately one binding site per monomer $(n=0.77)$. 


\section{Notes}

1. LecB is a calcium-dependent lectin and it is advised to maintain a $\mathrm{CaCl}_{2}$ concentration of $100 \mu \mathrm{M}$ through the purification process. If needed, this concentration can be decreased to $10 \mu \mathrm{M}$.

2. LecB is a very robust protein that can be lyophilized and stored at $-20^{\circ} \mathrm{C}$ for months or years. It is only recommended to aliquot in small quantities to avoid repeating cycles of defreezing and refreezing.

3. For a perfect ITC measurement, the main recommendation is to avoid buffer mismatch. Use exactly the same buffer for the protein solution and the sugar solution.

4. Alternatives to Origin are available in the public domain. The suite of integrated software packages NITPIC, SEDPHAT and GUSSI offer powerful treatment of data with automated shape analysis of the injection peaks [24]. It also allows for integrating results from different calorimetric titration experiments into a global analysis

5. In the Origin software, the default units are calories. This could be change to international units Watt and Joules using the Tab ITC and then Display Watt/Joules.

\section{Acknowledgements}

The authors acknowledge support by the ANR PIA Glyco@Alps (ANR-15-IDEX-02), Labex ARCANE and CBH-EUR-GS (ANR-17-EURE-0003), and the French Cystic fibrosis association Vaincre la Mucoviscidose.

\section{References}

1. Govan JR, Deretic V (1996) Microbial pathogenesis in cystic fibrosis: mucoid Pseudomonas aeruginosa and Burkholderia cepacia. Microbiol Rev 60(3):539-574.

2. Mesaros N, Nordmann P, Plesiat P et al. (2007) Pseudomonas aeruginosa: resistance and therapeutic options at the turn of the new millennium. Clin Microbiol Infect 13(6):560-578.

3. Gilboa-Garber N (1982) Pseudomonas aeruginosa lectins. Methods Enzymol 83:378385.

4. Gilboa-Garber N, Katcoff DJ, Garber NC (2000) Identification and characterization of Pseudomonas aeruginosa PA-IIL lectin gene and protein compared to PA-IL. FEMS Immunol Med Microbiol 29(1):53-57.

5. Tielker D, Hacker S, Loris R et al. (2005) Pseudomonas aeruginosa lectin LecB is located in the outer membrane and is involved in biofilm formation. Microbiology 151(Pt 5):1313-1323.

6. Mitchell E, Houles C, Sudakevitz D et al. (2002) Structural basis for oligosaccharidemediated adhesion of Pseudomonas aeruginosa in the lungs of cystic fibrosis patients. Nat Struct Mol Biol 9:918-921.

7. Loris R, Tielker D, Jaeger K-E et al. (2003) Structural basis of carbohydrate recognition by the lectin LecB from Pseudomonas aeruginosa. J Mol Biol 331:861870.

8. Mitchell EP, Sabin C, Šnajdrová L et al. (2005) High affinity fucose binding of Pseudomonas aeruginosa lectin PA-IIL: $1.0 \AA$ Resolution crystal structure of the complex combined with thermodynamics and computational chemistry approaches. Proteins 58:735-748.

9. Perret S, Sabin C, Dumon C et al. (2005) Structural basis for the interaction between human milk oligosaccharides and the bacterial lectin PA-IIL of Pseudomonas aeruginosa. Biochem J 389:325-332. 
10. Wu AM, Wu JH, Singh T et al. (2006) Interactions of the fucose-specific Pseudomonas aeruginosa lectin, PA-IIL, with mammalian glycoconjugates bearing polyvalent Lewis(a) and ABH blood group glycotopes. Biochimie 88(10):1479-1492.

11. Sommer R, Wagner S, Varrot A et al. (2016) The virulence factor LecB varies in clinical isolates: consequences for ligand binding and drug discovery. Chem Sci 7:4990-5001

12. Boukerb A, Rousset A, Galanos N et al. (2014) Anti-adhesive properties of glycoclusters against Pseudomonas aeruginosa lung infection. J Med Chem 57:1027510289.

13. Wagner S, Sommer R, Hinsberger S et al. (2016) Novel strategies for the treatment of Pseudomonas aeruginosa infections. J Med Chem 59(13):5929-5969.

14. Baeriswyl S, Gan BH, Siriwardena TN et al. (2019) X-ray crystal structures of short antimicrobial peptides as Pseudomonas aeruginosa Lectin B complexes. ACS Chem Biol.

15. Roethlisberger P, Istrate A, Marcaida Lopez MJ et al. (2016) X-ray structure of a lectin-bound DNA duplex containing an unnatural phenanthrenyl pair. Chem Commun 52(26):4749-4752.

16. Boukerb AM, Decor A, Ribun S et al. (2016) Genomic rearrangements and functional diversification of lecA and lecB lectincoding regions impacting the efficacy of glycomimetics directed against Pseudomonas aeruginosa. Frontiers in Microbiology 7:811.

17. Pokorná $\mathrm{M}$, Cioci G, Perret $\mathrm{S}$ et al. (2006) Unusual entropy driven affinity of Chromobacterium violaceum lectin CV-IIL towards fucose and mannose. Biochemistry 45:7501-7510.

18. Sudakevitz D, Kostlanova N, Blatman-Jan G et al. (2004) A new Ralstonia solanacearum high affinity mannose-binding lectin RS-IIL structurally resembling the Pseudomonas aeruginosa fucose-specific lectin PA-IIL. Mol Microbiol 52:691-700.

19. Adam J, Pokorna M, Sabin C et al. (2007) Engineering of PA-IIL lectin from Pseudomonas aeruginosa - Unravelling the role of the specificity loop for sugar preference. BMC Struct Biol 736.

20. Lameignere E, Malinovská L, Sláviková M et al. (2008) Structural basis for mannose recognition by a lectin from opportunistic bacteria Burkholderia cenocepacia. Biochem J 411:307-318.

21. Šulák O, Cioci G, Lameignère E et al. (2011) Burkholderia cenocepacia BC2L-C is a super lectin with dual specificity and proinflammatory activity PLoS Pathogens 7:e1002238.

22. Dam TK, Brewer CF (2002) Thermodynamic studies of lectin-carbohydrate interactions by isothermal titration calorimetry. Chem Rev 102(2):387-429.

23. Sabin C, Mitchell EP, Pokorná M et al. (2006) Binding of different monosaccharides by lectin PA-IIL from Pseudomonas aeruginosa: Thermodynamics data correlated with X-ray structures. FEBS Lett 580:982-987.

24. Brautigam CA, Zhao H, Vargas $C$ et al. (2016) Integration and global analysis of isothermal titration calorimetry data for studying macromolecular interactions. Nat Protoc 11(5):882-894. 